\title{
Key non-metal ingredients for Cu-catalyzed "Click" reactions in glycerol: nanoparticles as efficient forwarders
}

\author{
Marta Rodríguez-Rodríguez, ${ }^{[a, b]}$ Patricia Llanes,${ }^{[b]}$ Christian Pradel,${ }^{[a]}$ Miquel A. Pericàs ${ }^{*[b]}$ and \\ Montserrat Gómez ${ }^{*[a]}$
}

\begin{abstract}
The effect of long-alkyl chain amines in Cul-assisted azide-alkyne cycloadditions of terminal alkynes with organic azides in glycerol and other eco-friendly solvents (water, ethanol) has been examined. The presence of these additives favors the in situ formation of $\mathrm{Cu}(\mathrm{I})$-based nanoparticles and results in an increase of reactivity. In glycerol, liquid phase Transmission Electron Microscopy (TEM) analyses enabled by the negligible vapor pressure of this solvent proved that $\mathrm{Cu}(\mathrm{I})$ nanoparticles are responsible of the observed catalytic activity. The wide variety of alkynes and azides where this effect has been investigated ( 14 combinations) confirms the role played by these additives in Cu-catalysed Huisgen cycloadditions.
\end{abstract}

\section{Introduction}

Copper-catalyzed azide-alkyne cycloaddition (CuAAC) reactions represents a succeeding method for the synthesis of 1,2,3-triazoles, ${ }^{[1]}$ as itemized by the thousands of works published in this field, ${ }^{[2 a]}$ including enantioselective CuAAC transformations. ${ }^{[2 \mathrm{~b}-\mathrm{c}]}$ This remarkable success is mainly due to the process versatility in terms of solvent compatibility, copper sources (salts, well-defined complexes, preformed nanoparticles, (un)supported systems), functional group tolerance and energy supplies (conventional heating, microwave activation) among others. However, this hands-on behavior leads to some concerns from an understanding point of view ("who does what'), associated to the lack of concluding studies in relation to CuAAC mechanism(s) ${ }^{\left[{ }^{[3]}\right.}$ in particular for in situ generated systems using $\mathrm{Cu}(\mathrm{I})$ starting materials. The most used precursors, copper halides, are quite insoluble in the common organic solvents, especially $\mathrm{Cul}^{\left[{ }^{[4]}\right.}$ The presence of any additive (impurity) can improve the solubility of copper species in the medium, inducing then an increase of catalytic activity. In this context, organic bases play a decisive task, favoring both the coordination to metal (as Lewis bases) and the formation of active intermediates such as copper acetylides. Particularly, polydentate nitrogen-based ligands have been proved as efficient copper partners, stabilizing $\mathrm{Cu}(\mathrm{I})$ species ${ }^{[5]}$ and enhancing the rate of CuAAC processes ${ }^{[6]}$ In this frame, $\mathrm{Cu}(\mathrm{I})$ complexes containing tris-(triazolyl)methane tripodal ligands, which are highly proficient in CuAAC reactions, ${ }^{[1 \mathrm{f}, 7]}$ represent an elegant approach to illustrate the role of Lewis bases (Chart 1). These ligands can efficiently stabilize catalytic precursors (I) and also intermediates acting as hemi-labile scaffolds (II), which generates vacant sites for the coordination of reagents (Chart 1).
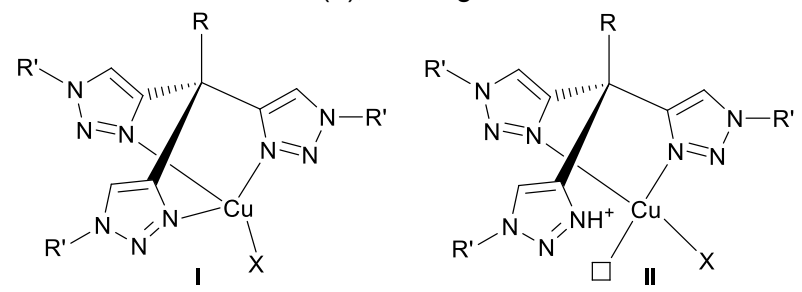

Chart 1. Tris(triazolyl)methane ligands for $\mathrm{Cu}(\mathrm{I})$-catalysed $A A C{ }^{[1 f, 7]}$ Small square denotes vacant site on copper.

In agreement with these important, ancillary tasks, base-free catalytic CuAAC systems are rare using $\mathrm{Cu}(\mathrm{I})$ complexes as copper source. To the best of our knowledge, only one recent publication by García-Alvarez and Vidal reports on a $\mathrm{Cu}(\mathrm{I}) \mathrm{system}$ able to catalyze CuAAC reactions in glycerol in the absence of any added base. ${ }^{[8]}$

[a] Ms. Marta Rodríguez, Mr. Christian Pradel, Prof. Montserrat Gómez Laboratoire Hétérochimie Fondamentale et Appliquée (LHFA) Université de Toulouse, UPS and CNRS UMR 5069

118, route de Narbonne, 31062 Toulouse cedex 9 (France) E-mail: gomez@chimie.ups-tlse.fr

[b] Ms. Marta Rodríguez, Dr. Patricia Llanes, Prof. Miquel A. Pericàs Institute of Chemical Research of Catalonia (ICIQ), The Barcelona Institute of Science and Technology

Avda. Països Catalans, 16, 43007 Tarragona (Spain)

E-mail: mapericas@iciq.es

Following our work on the use of glycerol as a solvent in metal-catalyzed processes ${ }^{[9]}$ and more recently in metal-free AAC for the synthesis of fully substituted $1,2,3$-triazoles, ${ }^{[10]}$ where the activation of both alkynes and benzylazide by glycerol was proved, we planned to evaluate the activity of $\mathrm{Cu}(\mathrm{I})$ salts towards click reactions in this solvent, with the aim of understanding the role of added exogenous base in glycerol medium.

Supporting information for this article is given via a link at the end of the document. 


\section{Results and Discussion}

We selected the cycloaddition between phenylacetylene and benzyl azide as the benchmark reaction, using Cul as catalyst source in neat glycerol at room temperature (Scheme of Table 1). The reaction did not work at all at short reaction times (1.5 h), $84 \%$ conversion being achieved after $24 \mathrm{~h}$ (entry 1, Table 1). In the course of our researchers, it was reported the high efficiency of this methodology under exactly the same "base-free" reaction conditions, triazole 1a being isolated by these authors in $94 \%$ yield in short reaction times. ${ }^{[8]}$ This serious discrepancy between independent runs of an easy-to-perform process, almost fulfilling the requirements in the Cornforth definition of an ideal chemical process ${ }^{[11]}$ led us to think that some uncontrolled factor was operating. Given the practical importance of azide-alkyne cycloadditions, we decided to deeply characterize the different components involved in the process in an attempt to rationalize this behavior. ${ }^{[12]}$ This analytical study showed that the reaction worked or not depending on the quality (source) of $\mathrm{BnN}_{3}$ (entries 2-4, Table 1) and that, rather surprisingly, high-purity samples of azide were unreactive. In fact only one commercially available lot of $\mathrm{BnN}_{3}$ favored the cycloaddition (entry 2, Table 1).

We analyzed the "active" $\mathrm{BnN}_{3}$ by GC-MS and NMR (Figs. S1-S3 in the Supplementary Information). In contrast to the other BnN $\mathrm{N}_{3}$ samples (Figs. S4-S9 in the Supplementary Information), this one was contaminated by some compounds which, according to MS, appeared to correspond to amines containing long-alkyl chains. To test the possible catalytic effect of these impurities, we carried out the cycloaddition in the presence of amines using high purity, home-made $\mathrm{BnN}_{3}$ (Table 2). We observed that using 5 mol\% of amine with respect to benzyl azide, primary (entries 1-3, Table 2), secondary (entry 4, Table 2) and tertiary (entry 5, Table 2) long-alkyl chainbased mono-amines led to high yields of the corresponding 1,2,3-triazole, 1a. For short-alkyl chain derivatives, such as triethylamine or diisopropylethylamine, low yields were achieved (<16\%, entries $6-7$, Table 2$)$. When the amount of added amine decreased (1 mol\%), the reaction also worked (entries 1 and 3-5, Table 2), especially for oleylamine, dioctyl and trioctyl amine (entries 3-5, Table 2). Ammonium salts, such as trioctylmethylammonium chloride (TOMACl) and Aliquat ${ }^{\circledR} 336$ (ammonium salt containing a mixture of $\mathrm{C} 8$ and C10 alkyl chains, often used as a metal extraction reagent ${ }^{[13]}$ ), did not favor the cycloaddition (entries 8-9, Table 2).

\begin{tabular}{|lll|}
\hline $\begin{array}{l}\text { Table 1. Azide-alkyne cycloaddition of phenylacetylene and benzyl } \\
\text { azide in the presence of Cul. }{ }^{\left[{ }^{2}\right]}\end{array}$ \\
\hline
\end{tabular}

Dinitrogenated (EN, o-PDA and PHEN, entries 11-13, Table 2) and tetranitrogenated (urotropine) ligands (entry 14, Table 2) did not trigger a positive outcome (yields $<12 \%$ ). TMEDA was an exception to this behavior $(70 \%$ yield, entry 10 , Table 2 ). The use of $2,6-$ lutidine, known by its performance in CuAAC in aqueous medium, ${ }^{[14]}$ gave very low yield (entry 15, Table 2).

The same trend could be found when phenyl azide was used instead of benzyl azide (entries 16-24, Table 2): the system was inactive in the absence of an added amine (entry 16, Table 2). While high isolated yields were recorded in the presence of amines containing a long-alkyl chain (up to $94 \%$, entries 17-20, Table 2). For "light" amines (entries 21-24, Table 2), only Cul/TMEDA system was active as observed with $\mathrm{BnN}_{3}$ (entries 10 and 22, Table 2).

Furthermore, this "magic" amine effect was examined in other polar solvents, such as water, ethanol or 1,4-dioxane. Under the same conditions than described above, the behavior was comparable to that observed in glycerol. In the absence of any additive or in the presence of NEt3, low yields were obtained $(<13 \%$, entries 1-6, Table 3 ). However in the presence of dioctylamine (entries $7-9$, Table 3) or oleylamine (entries 10-12, Table 3), the increase of catalytic activity was clearly apparent.

It is important to mention that the catalytic phase could be recycled up to four times without significant loss of efficiency (entry 3 , Table 2; see Fig. S10 in the Supporting Information), showing the ability of glycerol to immobilize the catalyst. The dramatic effect observed after the fourth run is undoubtedly related to the leaching of copper (more than 1,000 ppm determined by ICP-MS). 


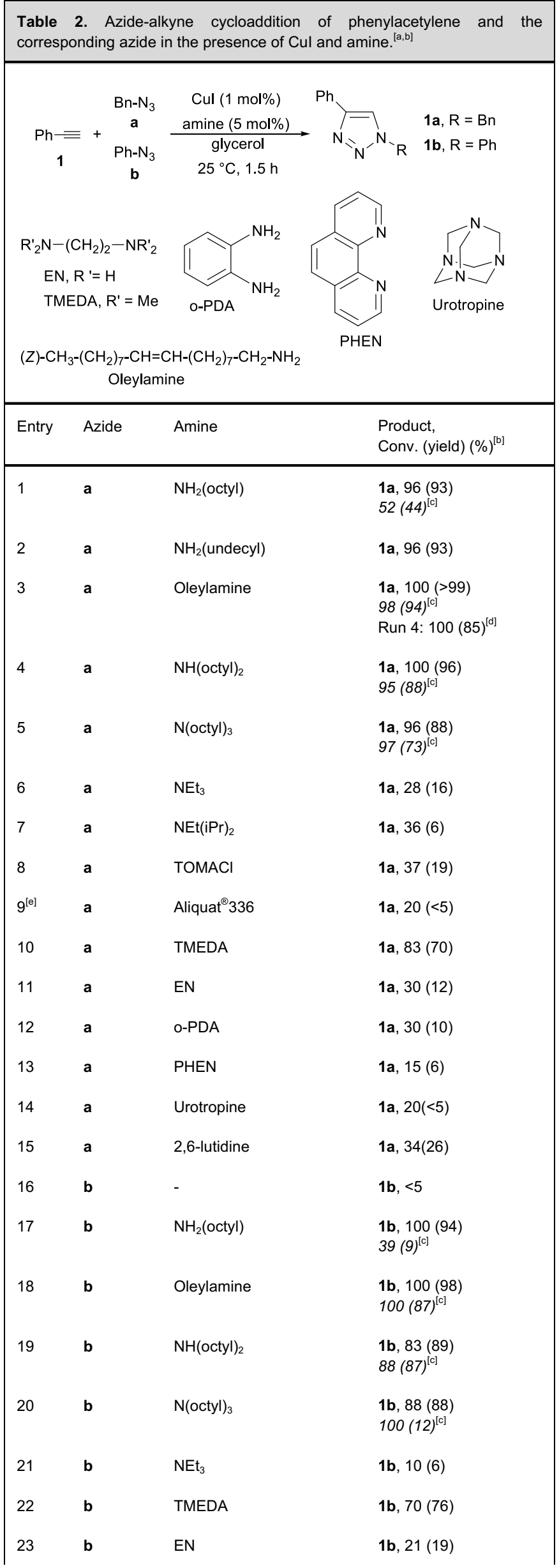


[a] Reaction conditions: Cul (1 mol\%), amine ( $5 \mathrm{~mol} \%)$, benzyl or phenyl azide $(0.5 \mathrm{mmol})$ and phenylacetylene $(0.5 \mathrm{mmol})$ in glycerol $(0.5 \mathrm{~mL})$ at $25^{\circ} \mathrm{C}$ for 1.5 h. [b] Determined by ${ }^{1} \mathrm{H}$ NMR analysis using 2-methoxynaphthalene or 1,3,5-trimethoxybenzene as internal standard; conversions based on $\mathrm{BnN}_{3}$. [c] In italics, conversion (yield) using $1 \mathrm{~mol} \%$ of amine. [d] See Fig. S10 for the recycling of the catalytic phase. [e] Aliquat ${ }^{\circledR} 336$ : ammonium salts containing a mixture of $\mathrm{C}_{8}$ and $\mathrm{C}_{10}$ alkyl chains with $\mathrm{C}_{8}$ predominating.

With these results in hand, a representative set of $\mathrm{Cu}$-catalyzed azide-alkyne cycloadditions involving the use of different alkynes (1-10) and organo-azides (a, b) (Fig. 1) was carried out in the presence of oleylamine. The corresponding triazoles were obtained in high to quantitative yield. Even those triazoles bearing alkyl substituents at C-4 (3a, 7a, 7b) were obtained in moderate-to-high yields (53-91\%). No transesterification reactions with glycerol were detected for alkynes containing ester groups (2a, 4a). For selected triazoles, the reactions were also carried out in the absence of added amine, as control experiments. In all cases, low yields $(<25 \%$, see Table S1 in the Supplementary information) were recorded even at longer times (up to $7 \mathrm{~h}$ ). Unfortunately, this catalytic system, working under smooth conditions, was not active using internal alkynes, such as diphenylacetylene or those more activated, methyl phenylpropiolate or 1-iodo-2-phenylacetylene (Fig. S11 in the Supporting Information).

With the aim of understanding the observed reactivity, we analyzed the structural behavior of copper salts. From a coordination point of view, the Cul motif leads to a large variety of structures corresponding to both discrete molecular complexes ${ }^{[15]}$ and polymeric networks, ${ }^{[16]}$ depending on the nature of the ligands involved and also the reaction conditions. This structural variety is especially remarkable when $\mathrm{N}$-based ligands are involved, ${ }^{[17]}$ in particular for diamines (EN, TMEDA, PHEN) and short-alkyl chain tertiary amines $\left(\mathrm{NEt}_{3}, \mathrm{NEt}^{\prime} \mathrm{Pr}_{2}\right)$ like those used in this work. ${ }^{[18]}$ Some of them give complex structures based on closed-cubane "Cu $\mathrm{Cu}_{4} \mathrm{l}_{4}$ " tetramers; ${ }^{[18 \mathrm{a}, 19]}$ we could prove this trend by the X-ray diffraction analysis of $\mathrm{Cu}_{4} \mathrm{l}_{4}$-TMEDA system (Figs. S12-S13 in the Supporting Information). ${ }^{[20]}$

\begin{tabular}{|c|c|c|c|}
\hline & $\mathrm{Ph} \frac{+}{\overline{1}}$ & $\underset{\mathrm{a}}{\mathrm{Bn}-\mathrm{N}_{3}} \stackrel{\mathrm{an}}{\mathrm{an}}$ & $\overbrace{\substack{\mathrm{N}^{-} \\
\mathrm{Pa}^{-\mathrm{N}}}}$ \\
\hline Entry & Solvent & Amine & Conv. (yield) $(\%)^{[b]}$ \\
\hline 1 & $\mathrm{H}_{2} \mathrm{O}$ & - & $22(13)$ \\
\hline 2 & $\mathrm{EtOH}$ & - & $12(<5)$ \\
\hline 3 & Dioxane & - & $11(<5)$ \\
\hline 4 & $\mathrm{H}_{2} \mathrm{O}$ & $\mathrm{NEt}_{3}$ & $15(<5)$ \\
\hline 5 & $\mathrm{EtOH}$ & $\mathrm{NEt}_{3}$ & $17(<5)$ \\
\hline 6 & Dioxane & $\mathrm{NEt}_{3}$ & $24(11)$ \\
\hline 7 & $\mathrm{H}_{2} \mathrm{O}$ & $\mathrm{NH}(\text { octyl })_{2}$ & $100(93)$ \\
\hline 8 & $\mathrm{EtOH}$ & $\mathrm{NH}(\text { octyl })_{2}$ & $66(48)$ \\
\hline 9 & Dioxane & $\mathrm{NH}(\text { octyl })_{2}$ & $100(99)$ \\
\hline 10 & $\mathrm{H}_{2} \mathrm{O}$ & Oleylamine & $99(94)$ \\
\hline 11 & $\mathrm{EtOH}$ & Oleylamine & $59(48)$ \\
\hline 12 & Dioxane & Oleylamine & $94(81)$ \\
\hline
\end{tabular}

[a] Reaction conditions: Cul (1 mol\%), amine ( $5 \mathrm{~mol} \%)$, benzyl or phenyl azide $(0.5 \mathrm{mmol})$ and phenylacetylene $(0.5 \mathrm{mmol})$ in the appropriate solvent $(0.5$ $\mathrm{mL})$ at $25^{\circ} \mathrm{C}$ for $1.5 \mathrm{~h}$. Triazole $1 \mathrm{a}$ was not obtained in the absence of copper (18\% conversion, $<5 \%$ yield for $1 \mathrm{a})$. [b] Determined by ${ }^{1} \mathrm{H}$ NMR analysis using 2-methoxynaphthalene or 1,3,5-trimethoxybenzene as internal standard; conversions based on $\mathrm{BnN}_{3}$.

In contrast, long-alkyl chain amines favor the stabilization of metal (and metal oxide) nanoparticles. ${ }^{[21]}$ Presuming the formation of copper-based nanoclusters under our reaction conditions, ${ }^{[22]}$ TEM analyses of Cul in glycerol and in the presence of different amines were carried out (Table S2 in the Supporting Information). Actually, the formation of well-dispersed nanoparticles was observed in the presence of long-alkyl chain amines, including ammonium derivatives (Fig. 2). HR-TEM and EDX analyses of Cul/dioctylamine mixture 
in glycerol confirmed the $\mathrm{Cu}(\mathrm{I})$ nature of the nanoparticles and the presence of the amine on the nanoparticles surface (Fig. S14 in the Supporting Information). It is worth noting that ammonium salts such as TOMACl and Aliquat ${ }^{\circledR} 336$ did not lead to catalytically active systems, although the formation of well-dispersed nanoparticles was also observed. The lack of catalytic activity in these last cases is probably due to the very strong electrostatic interaction between the ionic ligands and the nanoparticles: $\mathrm{Cu}(\mathrm{I})$-based nanoparticles are now tightly surrounded by anion/cation shells, and this leads to small and well-dispersed particles. However, this stabilizing interaction shields the nanoparticles surface and prevents the requisite approach of the reactants to the catalytic copper centers. By the contrary, hemi-labile amine ligands while still preventing particle agglomeration by steric shielding, can be easily detached leading to free coordination sites on copper for the reaction to proceed. ${ }^{[23]}$

$$
\text { glycerol }
$$

Figure 1. Scope of azide-alkyne cycloaddition catalysed by Cul/amine system in glycerol. Figures indicate isolated yields.

Interestingly, the presence of additional ionic compounds in the reaction medium could be shown to be not innocent. Thus, when an equimolar mixture of Aliquat ${ }^{\circledR} 336$ and a sodium salt $\left(\mathrm{NaOAc}\right.$ or $\left.\mathrm{NaN}_{3}\right)$ was added to the non-productive reaction mixture, the system turned into active (Fig. 3). TEM analyses of Cul in glycerol in the presence of both Aliquat ${ }^{\circledR} 336$ and sodium salt evidenced the formation of micelle-like arrangements, giving high local density of copper and therefore favoring the reactivity. This effect can be specially observed in the case of the mixture Aliquat ${ }^{\circledR} 336 / \mathrm{NaOAc}$, where cylindrical micelles were identified, containing the copper species at the surface (accessible to the reagents) and the more hydrophobic constituents (ammonium alkyl species) probably placed inside of these nano-objects. A similar trend could be observed using TOMACI/NaN 3 (Fig. S15 in the Supporting Information). It is important to note that $\mathrm{Cul} / \mathrm{NaN}_{3}$ and $\mathrm{Cul} / \mathrm{NaOAc}$ systems (in the absence of any nitrogen-based ligand) were not active. In addition, this reactivity behavior points to the feasibility of CuAAC by one-pot three-component approach. Actually, using as starting materials $\mathrm{Bn}-\mathrm{Br}, \mathrm{NaN}$ and phenylacetylene, 1a was obtained in $90 \%$ isolated yield (see Scheme S1 in the Supporting Information)

Correlating reactivity and structures, it seems that the formation of nanoparticles favors the catalytic process, what points to a beneficial (cooperative) effect between neighboring $\mathrm{Cu}(\mathrm{I})$ centers for the activation of both azide and alkyne reactants during the cycloaddition, as already noted in our previous work involving the use of $\mathrm{Cu}_{2} \mathrm{O}$ nanoparticles as catalytic precursors in glycerol medium. ${ }^{[9 a]}$
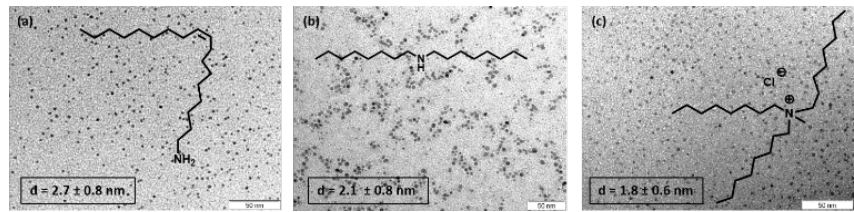

Figure 2. TEM images for Cul-based systems containing oleylamine (a), dioctylamine (b) and TOMACl (c) in glycerol.

In fact, for short-chain alkyl amines such as DIPEA, ethylenediamine or urotropine, agglomerates similar to those observed for $\mathrm{Cul}$ in the absence of any additive, were formed (Table S2 in the Supporting Information), affording inactive catalytic systems (Table 
2). Only Cul/TMEDA led to the simultaneous formation of nanoparticles and agglomerates. As we have already mentioned, this system depicted high catalytic activity in azide-alkyne cycloadditions (entries 10 and 22, Table 2).

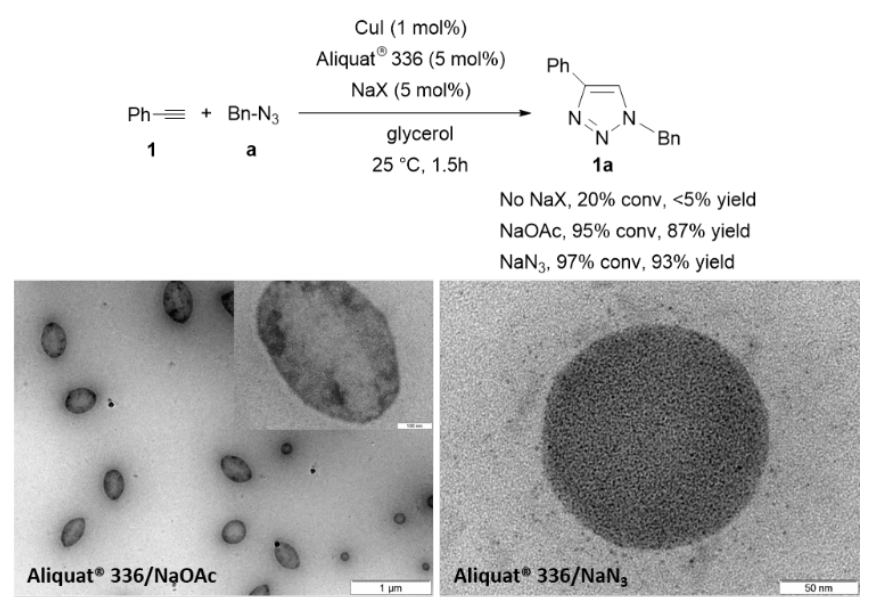

Figure 3. Effect of the salts in azide-alkyne cycloaddition. TEM images corresponding to the mixtures of Cul, Aliquat ${ }^{\circledR} 336$ and $\mathrm{NaX}$ (1/5/5 ratio, respectively): NaOAc (left), including an inserted image of one of the cylindrical micelle-like objects; $\mathrm{NaN}_{3}$ (right).

We were also interested in establishing the oxidation state of copper involved in the active species. For that, we reused the catalytic phase corresponding to the active Cul/dioctylamine system (after reaction between phenylacetylene and benzyl azide); TEM analysis after catalysis showed smaller nanoparticles than before (ca. $1.4 \mathrm{~nm}$ (after) vs $2.1 \mathrm{~nm}$ (before); Table S2 in the Supporting Information); the catalytic phase was then much less active (33\% in the second run vs $100 \%$ in the first one). HR-TEM coupled to an electronic diffraction analysis showed that particles after the first catalytic run were mainly constituted by $\mathrm{Cu}(0)(\mathrm{Fig}$. S16 in the Supporting Information). This indicate us that the initially formed $\mathrm{Cu}(\mathrm{I})$-rich nanoparticles suffer reductive deactivation as a concomitant off-cycle of CuAAC reaction In contrast, the reutilization of Cul/oleylamine system gave the same activity than for the first run (for both cases, nearly full conversion); HR-TEM/electronic diffraction analysis proved that nanoparticles were in this case mainly formed by $\mathrm{Cu}(\mathrm{I})$ after catalysis (Fig. S17 in the Supporting Information). In addition, XPS analyses evidenced the absence of Cu(II) species after reaction (absence of the corresponding strong satellites) (see Fig. S18 in the Supporting Information). These data point to $\mathrm{Cu}(\mathrm{I})$-based nanoparticles as responsible of the reactivity observed.

\section{Conclusions}

In this work, we could prove the key role of "impurities" randomly present in commercial samples of benzyl azide. Its accurate analyses led us to identify them (long-alkyl chain amines) and to examine their impact on Cul-based catalytic systems applied in azidealkyne cycloadditions in different solvents. As a practical result of this study, we have been able to establish that the addition of small amounts $(5 \mathrm{~mol} \%)$ of primary, secondary and tertiary amines containing $C_{8}, C_{11}$ and $C_{18}$ carbon chains (Cul/amine ratio $=1 / 1$ or $1 / 5$ ) secures the success in the synthesis of 1,4-disubstituted 1,2,3-triazoles under mild reaction conditions (low metal loading -1 mol\%-, short time $-1.5 \mathrm{~h}$ - and room temperature), in eco-friendly glycerol. As a corollary, a warning should be made on experimental procedures for CuAAC reaction in polar solvents not involving the use of appropriate amines: Their success or failure hardly depends on the presence/absence of amine-type impurities in the employed azide. The use of glycerol as a non-volatile solvent enabled the analyses of solutions constituted by Cul and amine, before and after catalysis, by (HR)TEM. It could be learned from these studies that Cul, in the presence of long-alkyl chain amines in glycerol at room temperature, gives raise to the formation of small and well-dispersed $\mathrm{Cu}(\mathrm{I})$ nanoparticles, in contrast with the agglomerates formed from either bulk Cul or from mixtures of Cul with low-weight amines. It is important to mention that the presence of ammonium salts mainly containing $\mathrm{C}_{8}$ chains (TOMACl, Aliquat ${ }^{\circledR} 336$ ) did not give an efficient catalytic system in spite of the formation of well-dispersed nanoparticles, almost certainly caused by the stabilization of Cul nanoparticles by electrostatic effect, blocking the access of reagents to the $\mathrm{Cu}(\mathrm{l})$ centers. However tuning the ionic species present in the reaction medium, the catalytic system turned into active through the formation of organized systems.

Altogether, this study led us to establish a correlation between the in situ formation of $\mathrm{Cu}(\mathrm{I})$ nanoparticles in glycerol and other polar solvents and their catalytic activity. These nano-objects, generated thanks to the presence of long-alkyl chain amines, favor the activation of both reagents, alkyne and azide partners, by cooperative effect between neighboring $\mathrm{Cu}(\mathrm{l})$ centers.

The inconsistencies found working under the "same" conditions induce the desire to understand, discovering new issues for known reactions. The use of controlled-quality compounds (reagents, catalysts, solvents) permits to dramatically reduce the casual effects, establishing reproducible and sustainable protocols. 


\section{Experimental Section}

General procedure for the azide-alkyne cycloaddition. Cul $(0.9 \mathrm{mg}, 0.005 \mathrm{mmol})$ and the corresponding amine $(0.005-0.25 \mathrm{mmol})$ were added to $0.5 \mathrm{~mL}$ of glycerol in a Schlenck tube equipped with a stirring bar under Ar atmosphere. The alkyne $(0.5 \mathrm{mmol})$ and the azide $(0.5 \mathrm{mmol}: 67 \mathrm{mg}$ for $\mathrm{BnN}_{3}{ }^{[24]}$ and $60 \mathrm{mg}$ for $\mathrm{PhN}_{3}$ ) were added consecutively to the reaction medium. The mixture was stirred at $25^{\circ} \mathrm{C}$ for $1.5 \mathrm{~h}$ (or the stated time). The organic products were extracted from the catalytic mixture with dichloromethane $(6 \times 2 \mathrm{~mL})$. The combined chlorinated organic layers were filtered through a Celite ${ }^{\circledR}$ pad and the resulting filtrate was concentrated under reduced pressure. The products were purified by chromatography (silica gel short column, eluent: cyclohexane/ethyl acetate) in order to determine the isolated yields of the corresponding triazoles.

\section{Acknowledgements}

Financial support from the Centre National de la Recherche Scientifique (CNRS), the Universite de Toulouse 3 - Paul Sabatier, MINECO (grants CTQ2012-38594-C02-01 and CTQ2015-69136-R), DEC (grant 2014SGR827) and ICIQ Foundation are gratefully acknowledged. S. Ladeira and R. Brousses are acknowledged for the resolution of the XRD structure. M. R. thanks the CNRS and MINECO (CTQ2012-38594-C02-01) for a PhD grant.

Keywords: azide-alkyne cycloaddition $\cdot$ copper $\cdot$ nanoparticles $\bullet$ long-chain amines $\bullet$ glycerol

[1] For selected reviews, see: a) J. E. Hein, V. V. Fokin, Chem. Soc. Rev. 2010, 39, 1302-1315; b) S. Díez-González, Catal. Sci. Technol. 2011, 1, 166-178; c) F. Alonso, Y. Moglie, G. Radivoy, Acc. Chem. Res. 2015, 48, 2516-2528; d) E. Haldón, M. C. Nicasio, P. J. Pérez, Org. Biomol. Chem. 2015, 13, 9528-9550; e) S. Chassaing, V. Bénéteau, P. Pale, Catal. Sci. Technol. 2016, 6, 923-957; f) P. Etayo, C. Ayats, M. A. Pericàs, Chem. Commun. 2016, 52, 1997-2010.

[2] a) More than 3,400 references from SciFinder Scholar Database up to March 2016 (search containing "copper and azide alkyne cycloaddition" keywords). For selected recent asymmetric CuAAC contributions, see: b) T. Song, L. Li, W. Zhou, Z.-J. Zheng, Y. Deng, Z. Xu, L.-W. Xu, Chem. Eur. J. 2015, 21, 554558; c) F. Zhou, C. Tan, J. Tang, Y.-Y. Zhang, W.-M. Gao, H.-H. Wu, Y.-H. Yu, J. Zhou, J. Am. Chem. Soc. 2013, $135,10994-10997$.

[3] a) L. Jin, D. R. Tolentino, M. Melaimi, G. Bertrand, Sci. Adv. 2015, 1, e1500304; b) S. Calvo-Losada, M. S. Pino-González, J. J. Quirante, J. Phys. Chem. B 2015, 119, 1243-1258; c) R. Berg, B. F. Straub, Beilstein J. Org. Chem. 2013, 9, 2715-2750; d) D. Astruc, L. Liang, A. Rapakousiou, J. Ruiz, Acc. Chem. Res. 2012, 45, 630-640; e) M. Meldal, C. W. Tornoe, Chem. Rev. 2008, 108, 2952-3015; f) C. Wang, D. Ikhlef, S. Kahlal, J.-V. Saillard, D. Astruc, Coord. Chem. Rev. 2016, 316, 1-20.

[4] Solubility product constants for CuX: CuCl, $1.72 \times 10^{-7}$; CuBr, $6.27 \times 10^{-9}$; Cul, $1.27 \times 10^{-12}$; data from CRC Handbook of Chemistry and Physics, Ed. D. R. Lide, $90^{\text {th }}$ edition, 2009-2010, CRC Press, Boca Raton.

[5] a) T. R. Chan, R. Hilgraf, K. B. Sharpless, V. V. Fokin, Org. Lett. 2004, 6, 2853-2855; b) W. G. Lewis, F. G. Magallon, V. V. Fokin, M. G. Finn, J. Am. Chem. Soc. 2004, 126, 9152-9153.

[6] a) V. O. Rodionov, S. I. Presolski, D. Díaz Díaz, V. V. Fokin, M. G. Finn, J. Am. Chem. Soc. 2007, 129, 12705-12712; b) V. O. Rodionov, S. I. Presolski, S. Gardinier, Y.-H. Lim, M. G. Finn, J. Am. Chem. Soc. 2007, 129, 12696-12704; c) S. I. Presolski, V. Hong, S.-H. Cho, M. G. Finn, J. Am. Chem. Soc. 2010, 132, 14570-14576.

[7] For selected contributions, see: a) S. Ozçubukçu, E. Ozkal, C. Jimeno, M. A. Pericàs, Org. Lett. 2009, 11, 4680-4683; b) E. Ozkal, P. Llanes, F. Bravo, A. Ferrali, M. A. Pericàs, Adv. Synth. Catal. 2014, 356, 857-869.

[8] C. Vidal, J. García-Alvarez, Green Chem. 2014, 16, 3515-3521.

[9] a) F. Chahdoura, C. Pradel, M. Gómez, ChemCatChem 2014, 6, 2929-2936; b) F. Chahdoura, S. Mallet-Ladeira, M. Gómez, Org. Chem. Front. 2015, 2, 312-318; c) F. Chahdoura, I. Favier, C. Pradel, S. Mallet-Ladeira, M. Gómez, Catal. Commun. 2015, 63, 47-51; d) F. Chahdoura, I. Favier, M. Gómez, Chem. Eur. J. 2014, 20, 10884-10893; e) F. Chahdoura, C. Pradel, M. Gómez, Adv. Synth. Catal. 2013, 355, 3648-3660.

[10] M. Rodríguez-Rodríguez, E. Gras, M. A. Pericàs, M. Gómez, Chem. Eur. J. 2015, 21, 18710.

[11] "It does, for example, no good to offer an elegant, difficult and expensive process to an industrial manufacturing chemist, whose ideal is something to be carried out in a disused bathtub by a one-armed man who cannot read, the product being collected continuously through the drain hole in $100 \%$ purity and yield" (J. Cornforth, Chem. Brit. 1975, 432).

[12] Different glycerol sources and different commercially available Cul salts were tested without observing any effect on the reactivity.

[13] For representative recent contributions, see: a) S. Sharma, C.-M. Wu, N. Rajesh, RSC Adv. 2016, 6, 26668-26678; b) S. S. Swain, B. Nayak, N. Devi, S. Das, N. Swain, Hydrometallurgy 2016, 162, 63-70.

[14] a) J. García-Álvarez, J. Díez, J. Gimeno, Green Chem. 2010, 12, 2127-2130; b) J. García-Álvarez, J. Díez, J. Gimeno, F. J. Suárez, C. Vincent, Eur. J. Inorg. Chem. 2012, 5854-5863.

[15] For selected contributions, see: a) M. Vitale, P.C. Ford, Coord. Chem. Rev. 2001, 219-221, 3-16; b) F. De Angelis, S. Fantacci, A. Sgamellotti, E. Cariati, R. Ugo, P.C. Ford, Inorg. Chem. 2006, 45, 10576-10584.

[16] For selected contributions, see: a) S. Kitagawa, R. Kitaura, S.-i. Noro, Angew. Chem. Int. Ed. 2004, 43, 2334-2375; b) G. Férey, Chem. Soc. Rev. 2008, 37, 191-214; c) A. J. Blake, N. R. Brooks, N. R. Champness, L. R. Hanton, P. Hubberstey, M. Schröder, Pure Appl. Chem. 1998, 70, 2351-2357.

[17] a) R. Peng, M. Li, D. Li, Coord. Chem. Rev. 2010, 254, 1-18; b) S. Yuan, H. Wang, D.-X. Wang, H.-F. Lu, S.-Y. Feng, S. Sun, CrystEngComm. 2013, 15, 7792-7802.

[18] For selected contributions, see: a) X. Chai, S. Zhang, Y. Chen, Y. Sun, H. Zhang, X. Xu, Inorg. Chem. Commun. 2010, 13, 240-243; b) Y. Yang, W. Chai, L. Song, K. Shu, Acta Cryst. 2010, E66, m1486; c) J.-H. Yu, J.-Q. Xu, L. Han, T.-G. Wang, Z. Shi, W.-J. Jing, H. Dong, J.-N. Xu, H.-B. Jia, J. Hua, Chinese J. Chem. 2002, 20, 851-857; d) M. F. Garbauskas, D. A. Haitko, J. S. Kasper, J. Crys. Spec. Res. 1986, 16, 729-738; e) P. C. Healy, C. Pakawatchai, C. L. Raston, B. W. Skelton, A. H. White, J. Chem. Soc. Dalton Trans. 1983, 1905-1916.

[19] S. Zhang, Y. Cao, H. Zhang, X. Chai, Y. Chen, R. Sun, J. Solid State Chem. 2008, 181, 3327.

[20] X-ray diffraction structure recently published: J.-J. Shen, J. Song, T.-L. Yu, Y.-L. Fu, Chin. J. Struct. Chem. 2014, 33, 1025-1030.

[21] For selected contributions, see: a) C. Pan, K. Pelzer, K. Philippot, B. Chaudret, F. Dassenoy, P. Lecante, M.-J. Casanove, J. Am. Chem. Soc. 2001, 123, 7584-7593; b) G. Salas, C. C. Santini, K. Philippot, V. Collière, B. Chaudret, B. Fenet, P. F. Fazzini, Dalton Trans. 2011, 40, 4660-4668; c) J. Cure, Y. Coppel, T. Dammak, P. F. Fazzini, A. Mlayah, B. Chaudret, P. Fau, Langmuir 2015, 31, 1362-1367.

[22] For recent contributions concerning Cu-based nanoparticles, see: a) M. B. Gawande, A. Goswami, F.-X. Felpin, T. Asefa, X. Huang, R. Silva, X. Zou, R. Zboril, R. S. Varma, Chem. Rev. 2016, 116, 3722-3811; b) H. R. Ong, M. M. R. Khan, R. Ramli, Y. Du, S. Xi, R. M. Yunus, RSC Adv. 2015, 5, 24544-24549.

[23] For a selected review concerning the stabilisation of metal nanoparticles, see: A. Roucoux, J. Schulz, H. Patin, Chem. Rev. 2002, 102, 3757-3778.

[24] S. G. Alvarez, M. T. Alvarez, Synthesis 1997, 413-414. 


\section{Entry for the Table of Contents}

\section{FULL PAPER}

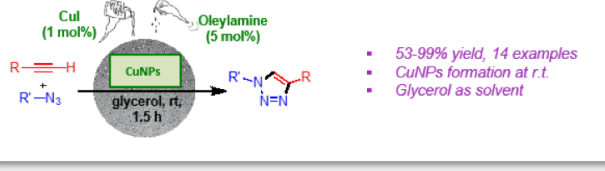

The noteworthy reactivity observed in CuAAC reactions, using Cul in the presence of long-chain amines as starting catalytic materials, could be correlated to the in situ formation of $\mathrm{Cu}(\mathrm{I})$ nanoparticles. These amines, acting as "magic" ingredients, become crucial for accelerating the process, in particular in glycerol medium.
Marta Rodríguez-Rodríguez, Patricia Llanes, C. Pradel, Miquel A. Pericàs* and Montserrat Gómez*

Page No. - Page No.

Key non-metal ingredients for $\mathrm{Cu}$ catalyzed "Click" reactions in glycerol: nanoparticles as efficient forwarders 